\title{
The Relationship between Intracellular and Extracellular Potassium in Normal and Malnourished Subjects as Studied in Leukocytes
}

\author{
JOHN PATRICK ${ }^{(33)}$ \\ Tropical Metabolism Research Unit, University of the West Indies, Mona, Kingston, Jamaica, West Indies
}

\begin{abstract}
Summary
Leukocyte potassium has been measured in normal subjects and in malnourished children with and without edema both on admission and during recovery. In nonedematous malnourished children the potassium content was low ( $328 \mathrm{mmol} / \mathrm{kg}$ dry solids) and took 2-3 weeks of rehabilitation to return to normal $(374 \mathrm{mmol} / \mathrm{kg}$ dry solids). Leukocytes from edematous children had normal intracellular potassium values. However, 5 days on a maintenance diet reduced the intracellular potassium in the children with kwashiorkor to a value similar to that found in marasmus. Plasma potassium was significantly lower in kwashiorkor (3.43) than in marasmus (4.74), The relationship between external potassium and internal potassium in normal leukocytes was measured (Fig. 1) and the values found in severe malnutrition compared with normal. It was found that in nonedematous malnutrition intracellular potassium was low compared to the predicted value, whereas in kwashiorkor, although the mean values were normal, no relationship between external potassium and intracellular potassium could be demonstrated. It is concluded that in the leukocyte malnutrition alters either the passive permeability of the membrane to potassium or the active transport of potassium, or both.
\end{abstract}

\section{Speculation}

Intra- and extracellular potassium are normally related in leukocytes; therefore, the measurement of the relationship between plasma and leukocyte potassium may provide a means of distinguishing between simple negative balance for potassium and potassium depletion secondary to a disorder of membrane function.

There is no simple, easily repeatable measurement which will give an indication of potassium status in severely ill patients. Less than $5 \%$ of body potassium is present in the extracellular fluid so that comparatively trivial shifts to or from the cells, particularly in the presence of impaired renal function, will induce large changes in plasma potassium. In addition, because behavior or the sodium potassium exchange pump or "sodium pump" has not been defined in most pathologic states, we cannot predict the relationship between plasma potassium and intracellular potassium in disease. Small changes in the "passive" permeability characteristics of the cell membrane or larger reductions in the activity of the sodium pump would lead to changes in the relationship between extracellular potassium and intracellular potassium. With these considerations in mind it is not surprising that Flear et al. (9) and Moore et al. (20) found no relationship between total exchangeable potassium and plasma potassium in a group of patients with a variety of severe illnesses.

The possible methods for measuring potassium status in man have been recently reviewed (24). They include whole body counting of ${ }^{40} \mathrm{~K}$, which requires expensive equipment, measurement of total exchangeable potassium with ${ }^{42} \mathrm{~K}$, which raises ethical prob- lems in children, muscle biopsy, which cannot be repeated often in children, or measurement of potassium in cells obtained from blood. Unfortunately, there is a reciprocal relationship between hemoglobin and intracellular potassium (millimoles per kg dry solids) in red blood cells (18) which necessitates a correction for hemoglobin before results can be interpreted (14). This phenomenon can lead to misleading estimates of potassium requirements if based upon red cell measurements (16). Leukocytes are the only other readily available cells. Leukocyte potassium has been shown to be a good measure of change in potassium status compared to total exchangeable potassium and potassium balance in simple dietetically induced potassium depletion (23). In this situation plasma potassium was also a useful indicator, confirming a previous statement by Welt (30). On the other hand, in uremia, where impairment of the sodium pump is well documented (22), there was no relationship between plasma potassium and leukocyte potassium. The other advantages of leukocytes have been emphasized by Baron (4).

The purpose of this paper is to present a series of measurements of potassium in leukocytes obtained from malnourished children and to relate the results to the extensive literature concerned with potassium metabolism in these children. This literature has been excellently reviewed $(2,11)$. Finally, the value of relating intraand extracellular potassium is illustrated by comparing the results obtained in leukocytes from malnourished children with those obtained from normal subjects.

\section{SUBJECTS AND METHODS}

\section{SUBJECTS}

The subjects were children admitted to the Tropical Metabolism Research Unit of the University of the West Indies, Kingston, Jamaica. They were all severely malnourished and were diagnosed as either kwashiorkor, marasmic kwashiorkor, or marasmus according to the Wellcome Classification (29). Written permission for the investigation was obtained from the parents after explaining the nature of the investigation and, in particular, its lack of immediate benefit to the children. The children selected for the study did not have severe gastroenteritis or severe acid-base disturbance at the time of study.

After admission the children were placed initially on a "maintenance diet" providing $95 \mathrm{cal} / \mathrm{kg} / 24 \mathrm{hr}$ and $0.6 \mathrm{~g}$ protein $/ \mathrm{kg} / 24$ $\mathrm{hr}$. The diet was supplemented with potassium $(4 \mathrm{mmol} / \mathrm{kg} / 24 \mathrm{hr})$ magnesium (mmol $/ \mathrm{kg} / 24 \mathrm{hr}$ ), iron, and vitamins. This diet, unlike their previous diet, contained all necessary nutrients, but only sufficient protein and energy to maintain body weight. This period is sufficient to allow repletion of a simple dietary deficiency of potassium (7) and also allows time for at least some improvement in vitamin and other nutrient deficits.

After this initial period, usually 5-10 days, the children were given a milk-based diet supplemented with oil which provided 135 $\mathrm{cal} / 100 \mathrm{ml}$ and $3.1 \mathrm{~g}$ protein $/ 100 \mathrm{ml}$. The children were fed every 
$4 \mathrm{hr}$ ad libitum and usually consumed between 150 and 200 $\mathrm{cal} / \mathrm{kg} / 24 \mathrm{hr}$. This regime has been described by Ashworth (3). Supplementation of the diet with potassium and magnesium was continued for 3 weeks. The potassium content of the unsupplemented diet was $36 \mathrm{mmol} / \mathrm{liter}$.

Studies were performed on admission, after loss of edema on the maintenance diet, during rapid weight gain, and on recovery, which was defined as the time when the child reached expected weight for length using Stuart and Stevenson's standards (27). The time for loss of edema varied from 1-18 days with a median value of 7 .

\section{TIMING OF STUDIES}

Children with edema were studied between days 1 and 5 with a median value of 1 . Studies after loss of edema were performed between days 3 and 18 with a median value of 7 . Marasmic children were studied between days 1 and 13 with a median value of 2 . The studies during rapid growth were in the early phase between days 9 and 30 with a median value of 15 . Studies on recovered children were performed between days 23 and 155 with a median value of 65 .

The edema-free weights of the children with kwashiorkor ranged from $4.7-11.7 \mathrm{~kg}$ with a median value of $7.0 \mathrm{~kg}$. Their ages ranged from 6-27 months with a median value of 13 months.

The marasmic children weighed between 3.5 and $6.8 \mathrm{~kg}$ (median value $5.1 \mathrm{~kg}$ ). Their ages ranged between 6 and 19 months (median value 12 months). The children with kwashiorkor therefore received an average of $40 \%$ more potassium than the marasmic children. All children received a daily supplement of potassium equivalent to approximately one-tenth of their whole body potassium.

\section{METHOD OF OBTAINING CELLS}

The method of obtaining the cells is essentially that described by Baron and Ahmed (5) with the following minor modifications. Blood, 8-10 ml, was taken from a large vein into a syringe. A small portion was set aside for measurement of plasma electrocytes and to the syringe was added $2.5 \mathrm{ml}$ dextran 250 (Pharmacia, Sweden) in Kreb's bicarbonate buffer ( $\mathrm{pH} 7.4$ ). The syringe was then inverted and sedimentation allowed for 20-25 min. The leukocyte-rich supernatant was then removed from the syringe through suitable polythene tubing (a pediatric scalp vein infusion set with the needle removed works well). The leukocyte-rich supernatant was then centrifuged twice, at $160 \mathrm{~g}$ for $5 \mathrm{~min}$ and again at $200 \mathrm{~g}$ for $3 \mathrm{~min}$ in polystyrene tubes (contact with glass should be avoided at all times). The pellets of mixed leukocytes and erythrocytes were resuspended in the minimum quantity of buffer and subjected to hypoosmolal lysis with distilled water for $13 \mathrm{sec}$, after which isoosmolality was restored with hyperosmolar Hartman's solution. The cells were then incubated in Kreb's bicarbonate buffer ( $\mathrm{pH} 7.4$ ) with $6 \mathrm{mmol}$ glucose. The sodium and potassium concentrations were adjusted to those of the plasma. After 20 min the cells were centrifuged in the preweighed plastic bags described by Baron and Ahmed (5) (1969) (some types of flat polythene tubing contain substances which cause an increase in intracellular sodium). The cells were dried to constant weight in a freeze drier, then reweighed and digested in $0.1 \mathrm{M} \mathrm{HNO}_{3}$ overnight before reading by flame photometry (Instrumentation Laboratory 343 ).

The results can then be expressed as millimoles per $\mathrm{kg}$ dry solids without the use of an extracellular fluid correction because in the final specimen more than $98 \%$ of both solids and potassium are intracellular. The values obtained with and without an extracellular fluid marker were usually within $1 \%$ of each other, the maximum difference being $7 \mathrm{mmol}(n=19$ pairs, means 378 and 381 ). The value obtained without the ECF correction is always the higher.

The experiments to determine the relationship between intraand extracellular potassium in leukocytes obtained from normal subjects were performed at values for external potassium between 0 and $13 \mathrm{mmol} /$ liter. The protocol was essentially the same as that used for the measurement of potassium fluxes (15). The cells were obtained from healthy young adults except on three occasions where blood was available from 2- to 3-year olds who were having blood drawn for other reasons. The incubation time used was 40 min, which is long enough for equilibration to a new external potassium concentration to occur.

\section{RESULTS}

All of the values for leukocyte potassium are expressed as $\mathrm{mmol} / \mathrm{kg}$ dry solids. Leukocyte potassium was normal in children with edema but low after loss of edema. Intracellular potassium was low in marasmic children. Two to 3 weeks of high energy feeding were necessary for a return to normal values. Potassium supplementation during the period of maintenance energy feeding did not lead to an increase in leukocyte potassium content. The data is presented as a statistical summary in Table 1. Differences were tested by Student's $t$-test.

Because there is a relationship between external and internal potassium in normal leukocytes, we were interested to see whether this persisted in the malnourished state. The normal relationship obtained in cells largely obtained from young adults is shown in Figure 1. It can be seen that cells obtained from marasmic children have lower than expected intracellular potassium values for their plasma potassium, whereas those from children with edema were nearer to the predicted value. Plasma potassium values were lower in kwashiorkor than marasmus (Table 1). This difference persisted even when careful matching for time of sampling was included in the analysis to avoid any disproportionate effect of the routine potassium supplementation. Thus, comparison of plasma potassium values obtained on day 1 showed that children with edema had a plasma potassium of $3.1 \pm 0.25(\mathrm{SEM}) \mathrm{mmol} / \mathrm{liter}$ and children with marasmus $4.1 \pm 0.27$ (SEM) mmol/liter $(P<0.05)$.

Table 1. Summary of results obtained from 98 measurements of leukocyte potassium (millimoles per kg dry solids) in malnourished children ${ }^{1}$

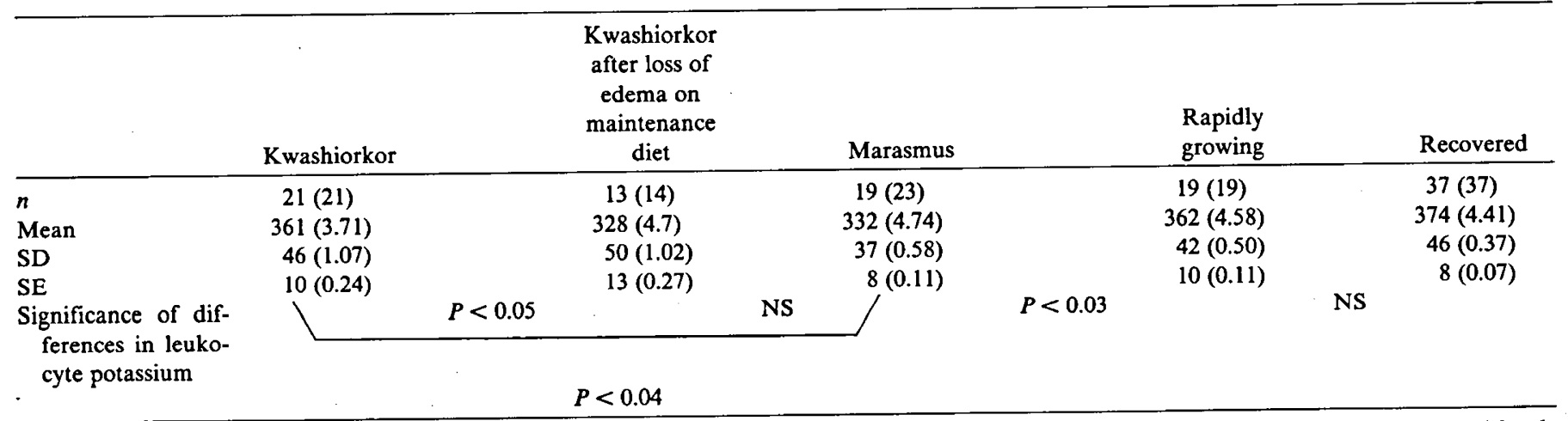

\footnotetext{
${ }^{1}$ Plasma potassium values are shown in parentheses. The change in plasma potassium associated with loss of edema was significant at the $5 \%$ level.
} 


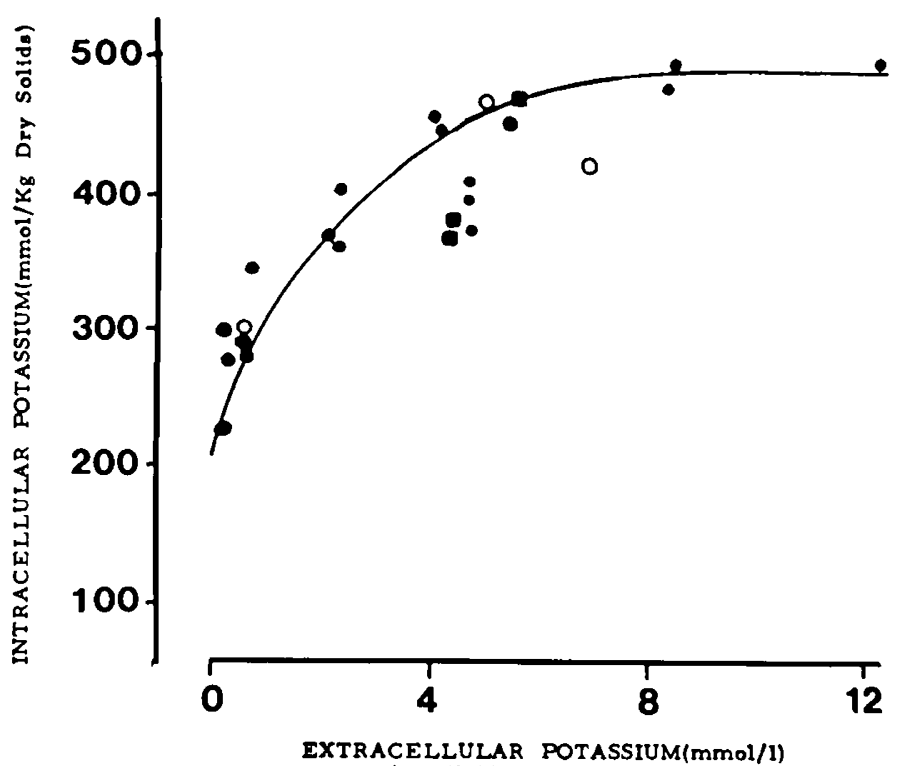

Fig. 1. The effect of variations in external potassium on intracellular potassium. $\square$, cells incubated initially at a potassium concentration of 0 and then transferred for $20 \mathrm{~min}$ to the concentration indicated. The line was drawn by eye and is intended only as a guide in the interpretation of Figure 2. $\bullet$, measurements in adults; $\bigcirc$, measurements in infants.

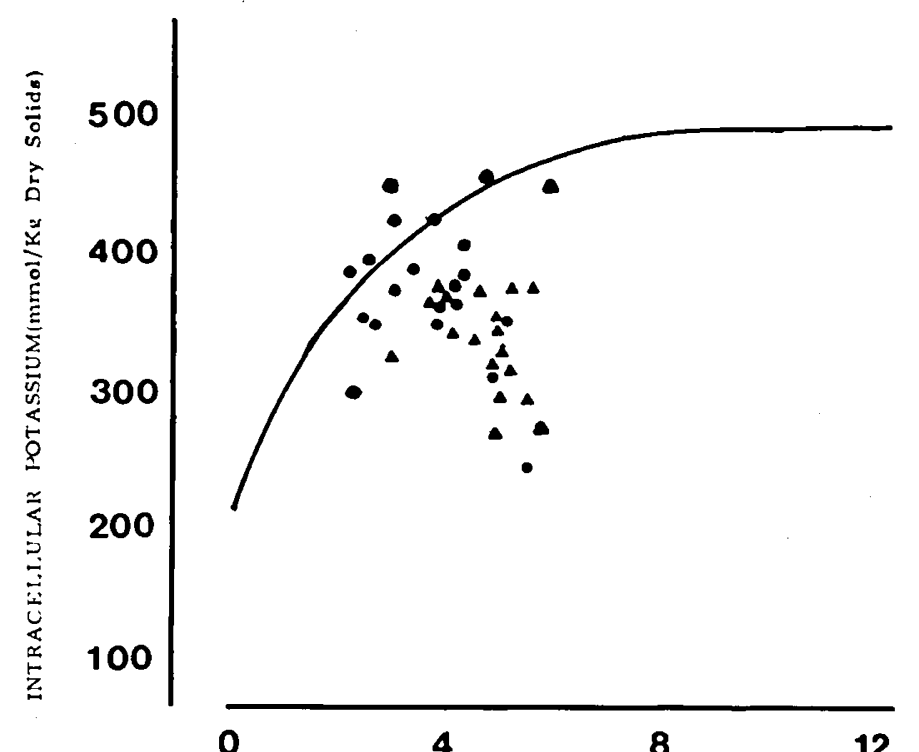

0 4

be impaired in protein-energy malnutrition beyond the degree which would be expected from simple potassium deficiency. This conclusion has been demonstrated to be justified (25).

\section{DISCUSSION}

The results presented here indicate that considerable changes in leukocyte electrolyte metabolism occur in severe malnutrition. The finding of a reduction in leukocyte potassium of approximately $15 \%$ in malnourished children without edema compared to children who had recovered was similar to results obtained from whole body counting of ${ }^{40} \mathrm{~K}$ in Jamaica (12) and South Africa (18) and from measurements of total exchangeable potassium with ${ }^{42} \mathrm{~K}$ in Jamaica (26). However, in Guatemala a much greater depletion was found in edematous children (21), possibly because of the much greater problem with gastroenteritis in Guatemala. Similar reductions in potassium have been found in muscle biopsies (10, 28 ), but where whole body potassium was severely reduced muscle lost a disproportionate amount (2).

Whole body studies have usually found that kwashiorkor was associated with lower potassium values than marasmus (12). However, in this study, leukocyte potassium in the presence of edema was normal whereas after loss of edema it reached the same low value found in marasmic children. There are three points to make in relation to this finding. First, whole body measurements using body weight as the reference unit would produce lower values in edematous children because of the increased extracellular fluid with its small potassium content even if the cellular potassium content were the same in marasmus and kwashiorkor. Most workers have attempted to correct for this by using minimal or edema free weight but even in the absence of edema the extracellular fluid space can be increased as much as $10 \%(8)$. Second, it is important to emphasize that the leukocytes were incubated in vitro for some $20 \mathrm{~min}$ before final preparation of the specimen and it is possible that potassium was gained during that period, as perusal of Figure 1 shows. Certainly this effect cannot be representative of the body as a whole because it has been shown that a gross negative balance for potassium does not occur in the period of loss of edema (21). Third, the effect of external potassium on internal potassium will be dependent upon intracellular sodium because of obligatory linkage between potassium influx and sodium efflux. A low intracellular sodium will limit the increase in potassium influx. Therefore, one would predict a small effect of external potassium on internal potassium in the red cell which has a very low intracellular sodium (approximately $5 \mathrm{mmol} / \mathrm{liter}$ cells) compared to the leukocyte (approximately $40 \mathrm{mmol} / \mathrm{liter}$ cell water). In this respect the red cell may be atypical of the body as a whole in that external $\mathrm{K}$ has also been shown to increase muscle potassium (6).

The increase in plasma potassium during the first few days had been commented upon previously. Kingston (17) has also drawn attention to the very low potassium values which occur in some children with kwashiorkor. It seems unlikely that this hypokalemia is a result of simple potassium deficiency. In one child we have studied the low plasma potassium persisted for 5 days despite 32 mmol oral potassium daily, i.e., nearly $50 \%$ of his expected total body potassium content. The eventual increase in plasma potassium correlated with a fall in leukocyte potassium which does seem to imply a fundamental defect in potassium physiology rather than a simple deficit dependent upon gastroenteritis or dietary inadequacy. Since this child was receiving $0.6 \mathrm{~g}$ protein $/ \mathrm{kg}$ the hypokalemia cannot be explained on the basis of the rapidly increasing cellular capacity for potassium which Alleyne et al. (2) emphasized as a reason for potassium retention during rehabilitation.

If the transport system were normal in the leukocytes obtained from malnourished children without edema then the expected value for leukocyte potassium for a plasma potassium of 4.0 would be in the range of $380-450$ (mmol/ $\mathrm{kg}$ dry solids), but it was 332 . We therefore conclude that the transport system in marasmus is not capable of responding to external potassium concentration in 
the normal way (13). Measurements of the rate constant for sodium efflux in leukocytes obtained from malnourished children support this view (23).

In the children with edema the mean plasma potassium for the whole group was 3.43, and the range was from 2.1-5.0. Despite this range there was no correlation between plasma potassium and intracellular potassium, although most intracellular values were within the normal range. Thus in kwashiorkor the major determinant of the behavior of the transport system appears not to be extracellular potassium. We therefore conclude that there is a second and different transport abnormality present in leukocytes obtained from children with kwashiorkor. This conclusion is supported by the entirely different time course and nutritional intake during the changes in leukocyte potassium associated with loss of edema compared to those associated with recovery of normal bodily proportions.

Leukocyte potassium measurements therefore give a similar picture of the process of potassium repletion in malnutrition unassociated with edema to that given by other methods of assessing potassium status. In kwashiorkor potassium measurements in leukocytes were relatively normal; however, consideration of the relationship between plasma and cellular potassium suggests that there is a fundamental change in the physiology of potassium which differs from the situation found in marasmus.

\section{REFERENCES AND NOTES}

1. Alleyne, G. A. O.: Mineral metabolism in protein-calorie malnutrition. In: R. E. Olson: Protein-calorie malnutrition (Academic Press, New York, 1975).

2. Alleyne, G. A. O., Millward, D. J., and Schullard, G. N.: Total body potassium, muscle electrolytes and glycogen in malnourished children. J. Pediat., 76: 75 (1970).

3. Ashworth, A.: Growth rates in children recovering from severe protein-calorie malnutrition. Brit. J. Nutr., 23: 835 (1966).

4. Baron, D. N.: Down with plasma! Intracellular chemical pathology studied by the analysis of cells, of solid tissues, and leucocytes. Proc. Roy. Soc. Med., 62 . 945 (1969).

5. Baron, D. N., and Ahmed, S. A.: Intracellular concentration of water and of the principal electrolytes determined by the analysis of isolated human leucocytes. Clin. Sci., 37: 205 (1969).

6. Bergstron, J., and Hultman, E.: Water, electrolyte and glycogen content of muscle tissue in patients undergoing regular dialysis therapy. Clin. Nephrol., 2: 24, (1974).

7. Black, D. A. K., and Milne, M. D.: Experimental potassium depletion in man. Clin. Sci., 11: 397 (1952).

8. Chobanian, A. V., Burrows, B. A., and Hollander, W.: Body fluid and electrolyte composition in cardiac patients with severe heart disease but without peripheral edema. Circulation, 24: 743 (1961).

9. Flear, C. T. G., Cooke, W. T., and Quinton, A.: Serum potassium as an index of body content. Lancet, $i: 458$ (1957).
10. Frenk, S., Metcoff, F., Gomez, R., Ramos-Galvan, J., Cravioto, X., and Antonowitz. I. Intracellular composition and homeostatic mechanisms in severe chronic infantile malnutrition. Pediatrics, 20: 105 (1957).

11. Garrow, J. S.: Total body potassium in kwashiorkor and marasmus. Lancet, $i$ : 455 (1965).

12. Garrow, J. S., Smith, R., and Ward, E. E.: Electrolyte Metabolism in Severe Infantile Malnutrition (Pergamon Press, London, 1968).

13. Glynn, I. M.: Sodium and potassium movements in human red cells. J. Physiol. (Lond.), 134: 278 (1956).

14. Hellerstein, S., and Surapathana, L.: Erythrocyte composition in diarroheal dehydration. J. Pediat., 78: 585 (1971).

15. Hilton, P. J., Edmondson, R. P. S., Thomas, R. D., and Patrick, J.: The effect of external potassium concentration on leucocyte cation transport in vitro. Clin. Sci. Mol. Med., 49: 385 (1975).

16. Keitel, H. G.: Comparison of the changes in the red cell potassium content with total body balance of potassium during potassium therapy. J. Lab. Clin. Med., 49: 267 (1957).

17. Kingston, M.: Electrolyte disturbances in Liberian children with kwashiorkor. J. Pediat., 83: 857 (1973).

18. Maizels, M.: The anion and cation content of normal and anaemic bloods. Biochem. J., 30: 821 (1936).

19. Mann, M. D., Bowie, M. D., and Hansen, J. D. L.: Total body potassium and serum electrolyte concentrations in protein energy malnutrition. S. Afr. Med. J., 49: 76 (1975).

20. Moore, F. D., Edelman, I. S., Olney, J. M., Jones, A. M., Brookes, L., and Wilson, G. M.: Body sodium and potassium: Interrelated trends in alimentary, renal and cardiovascular disease; lack of correlation between body stores and plasma concentration. Metabolism, 3: 334 (1954).

21. Nichols, B. L., Alvardo, J., Rodriquez, J., Hazlewood, C. F., and Viteri, F.: Therapeutic implications of electrolyte, water and nitrogen losses during recovery from protein-calorie malnutrition. J. Pediat., 84: 759 (1974)

22. Parker, J. C., and Welt, L. G.: Pathological alterations of cation movements in red blood cells. Arch. Int. Med., 129: 320 (1972).

23. Patrick, J.: Assessment of body potassium stores. Kidney Int., 11: 476 (1977).

24. Patrick, J.: Death during recovery from severe malnutrition and its possible relationship to sodium pump activity in the leucocyte. Brit. Med. J., I: 1051 (1977).

25. Patrick, J., and Bradford, B.: A comparison of leucocyte potassium content with other measurements in potassium depleted rabbits. Clin. Sci., 42: 415 (1972)

26. Smith, R., and Waterlow, J. C.: Total exchangeable potassium in infantile malnutrition. Lancet, $i$ : 147 (1960).

27. Stuart, M. C., and Stevenson, S. S.: In: W. Nelson: Textbook of Pediatrics (Saunders, Philadelphia, 1959).

28. Waterlow, J. C., and Mendes, C. B.: Composition of muscle in malnourished human infants. Nature, 180: 1361 (1957).

29. Wellcome Classification. Lancet, ii: 302 (1970).

30. Welt, L. G., Cap, M. P. Gehan, E. A., Winters, R. W., De Walt, J. L., and Diamond, E. L.: The prediction of muscle potassium from blood electrolytes in potassium depleted rats. Trans. Assoc. Amer. Physic., 71: 250 (1959).

31. The help of Mrs. H. MacDonald, Mrs. V. Johnson, and Mrs. E. Forrest is gratefully acknowledged.

32. This research was supported by a grant from the Wellcome Trust.

33. Requests for reprints should be addressed to: Dr. J. Patrick, Tropical Metabolism Research Unit, University of the West Indies, Mona, Kingston 7, Jamaica (WI).

34. Received for publication October 18, 1976.

35. Accepted for publication September 21, 1977. 